\title{
ОБЗОР ЛИТЕРАТУРЫ: ИММУНОПАТОГЕНЕЗ СИНДРОМА ДЛИТЕЛЬНОГО СДАВЛЕНИЯ
}

\section{LITERATURE REVIEW: IMMUNOPATHOGENESIS OF LONG-TERM COMPRESSION SYNDROME}

Yu. Kabartieva

A. Mollaeva

Summary. The article provides a review of the literature, according to which, to date, there are sufficiently convincing data indicating the pathogenetic significance of changes in the innate and adaptive immunity system in the syndrome of prolonged compression (SDS). This position is a "starting point" when starting the use of immunocorrection means in the complex treatment of such a serious condition as prolonged compression syndrome.

Keywords: congenital and adaptive immunity, prolonged compression syndrome, plasma.

\author{
Кабартиева Юлдуз Абдулхаликовна \\ Ассистент, Дагестанский Государственный \\ Медицинский Университет, г. Махачкала \\ kabartiyeva@list.ru \\ Моллаева Асма Магомедовна \\ Ассистент, Дагестанский Государственный \\ Медицинский Университет, г. Махачкала \\ asma.mollayeva.76@mail.ru
}

Аннотация. В статье дается обзор литературы, согласно которому, на сегодняшний день существуют достаточно убедительные данные, свидетельствующие 0 патогенетической значимости изменений в системе врождённого и адаптивного иммунитета при синдроме длительного сдавления (СДС). Это положение является "точкой отсчёта" при сновании применения средств иммунокоррекции в комплексном лечении такого тяжёлого состояния, как синдром длительного сдавления.

Ключевые слова: врожденные и адаптивный иммунитет, синдром длительного сдавления, плазма.

токсемия, а также микробные антигены активируют клетки иммунной системы, что сопровождается существенным увеличением уровня сывороточных провоспалительных цитокинов (ИЛ-1, ИЛ-6, ТНФ-а), активацией клеток макрофагально-моноцитарного ряда, сопряжённой с увеличением продукции микробицидной миелопероксидазы (МПО), активацией CD3+CD4+ и $\mathrm{CD} 3+\mathrm{CD} 8+$ клеток [2]. Гипермиоглобулинемия на этапе реваскуляризации сдавленных тканей коррелирует с индукцией патогенетически значимого ответа системы адаптивного иммунитета на этот антиген.

Крайне важны результаты исследований экспрессии TLR рецепторов на клетках врождённого иммунитета (дендритных клетках, макрофагах, естественных киллерах) при синдроме длительного сдавления. На экспериментальных моделях СДС показана патогенетическая роль селективной экспрессии TLR2, TLR4 и TLR9 рецепторов на клетках макрофагально-моноцитарного ряда и на лимфоцитах. Эта экспрессия сопряжена с достоверным увеличением пролиферативной активности спленоцитов и продукцией провоспалительных цитокинов (ИЛ-1, ТНФ-a), Th1+CD4+субпопуляцией лимфоцитов [5]. Весьма интересны данные, касающиеся вовлечённости клеток и рецепторов врождённого иммунитета в патогенез СДС. Показано, что супрессия пролиферативного ответа спленоцитов in vitro на мышиной модели компрессионной травмы сопряжена 
c TLR4- и TLR9-NF-kB сигнальными путями. Одновременно, авторы показывают вовлечённость TLR2+ и TLR4+ спленоцитов в начальные этапы системного воспаления и адаптивного иммунного ответа при СДС, однако этот ответ не зависел от TLR9+спленоцитов, подчёркивая тем самым селективность функционального предназначения TLR-рецепторов [6].

Эти и другие данные важны с той точки зрения, что индукция антиген-специфического иммунного ответа и продукции провоспалительных цитокинов при СДС возможна при условии активации клеток врождённого иммунитета через упомянутые TLR рецепторы.

Патогенетическая общность системного воспаления и транзиторной активации врождённого и адаптивного иммунитета при СДС доказана многими экспериментальными работами по СДС. В частности, высокие дозы дексаметазона, уменьшающие выраженность воспаления при СДС, а также ингибирующие транзиторную активацию врождённого и адаптивного иммунитета, достоверно снижают смертность крыс по истечении 48 часов после реперфузии [7]. Тяжёлые формы СДС связаны с выраженной стресс-реакцией, сопровождающейся гиперпродукцией гормонов надпочечников кортикостероидов и катехоламинов и, как следствие, формированием транзиторного вторичного иммунодефицита. Очевидно, что система адаптивного и врождённого иммунитета являются важными компонентами патогенеза СДС.

Иммуногистохимические исследования показали, что степень тяжести компрессионной травмы мышц на экспериментальных моделях связана с увеличением гистологических зон воспалительной клеточной инфильтрации и фиброза, усилением продукции провоспалительных цитокинов - ИЛ-1 $\beta$, ИЛ-6 и ТНФ- $a$ in situ и наличием признаков активации макрофагов и фибробластов [8].

СДС различной степени тяжести сопровождается активацией клеток макрофагально-моноцитарного ряда (CD14+, CD68+), а также клеток адаптивного иммунитета, в частности субпопуляций Т-лимфоцитов CD3+CD4+ и CD3+CD8+клеток $[95,121,150]$. Пик инфильтрации макрофагами места повреждения - на 2-5 день посткомпрессионного периода, а лимфоцитами - на 7 день [3]. Компрессионная травма индуцирует повышенную экспрессию антигенов I и II классов гистосовместимости (МНС) на клетках макрофагально-моноцитарного ряда, что является стимулом для индукции антиген-специфического адаптивного иммунного ответа на продукты рабдомиолиза [6]. Этот ответ имеет некоторые признаки аутоиммунного на основании фактов, согласно которым при травматическом повреждении, в частности, нервной ткани гиперпродукция провоспалительных цитокинов ТНФ- $\beta$, ИЛ-6 и ИЛ-22 индуцирует синтез ИЛ-17 Т-клетками, принимающих участие В т.ч. и в индукции аутоиммунитета и воспаления [5]. Гипермиоглобулинемия, на этапе реваскуляризации сдавленных тканей, сопровождается индукцией патогенетически значимого ответа системы адаптивного иммунитета на эти антигены. Через несколько часов после компрессионной травмы констатируется гиперпродукция провоспалительных цитокинов (ИЛ-1 $\beta$, ТНФ- $а$, ИЛ-6, ИФ-ү). Эти цитокины, взаимодействуя с рецепторами эндотелия, стимулируют хемотаксис нейтрофилов в место повреждения. Именно эти клетки выполняют основную "нагрузку" в отношении фагоцитоза клеточного и тканевого детрита и, активируясь, продуцируют микробицидную миелопероксидазу (МПО), выступающую в качестве важного компонента экстрацеллюлярных механизмов противомикробной защиты фагоцитирующих клеток [4]. С учётом представленных данных в настоящее время в комплекс лечебных мероприятий при СДС рекомендуется включать препараты, ингибирующие активность провоспалительных цитокинов [3].

В клетках печени, лёгких и почек после 12-часовой компрессии нижних лапок крыс определяются разрывы ДНК, что свидетельствует о значительной роли генетических изменений токсемической этиологии в патогенезе СДС [7]. Этот процесс сопряжён со снижением внутриклеточного синтеза белков - в цитозольном компартменте на 32,7\%, в митохондриях - на 49\%. 3начительна роль апоптоза в генезе СДС. TUNEL-анализ показал, что на мышиной модели ишемии/реперфузии камбаловидной мышцы мышей существенно возрастает уровень апоптотических телец в клетках почек и миоцитах. Доказательством усиления процессов апоптоза и их связи с оксидативным стрессом при СДС является повышение уровней мРНК таких молекул клеточной активации и стресса, как COX-2, C-FOS, Hsp70, а также ИЛ-6 [2]. В лейкоцитах, инфильтрирующих зону повреждения пик апоптоза наблюдается в первый день СДС, что позволило авторам сделать вывод о том, что степень тяжести компрессионной травмы коррелирует с локальными репаративными процессами [5]. Также показано увеличение активности каспаз 3 и 12, ферментов апоптоза, при экспериментальной компрессионной травме [6].

Показано, что при экспериментальном краш-синдроме индуцируется повышенный синтез ядерного протеина макрофагов - HMGB1. Этот протеин связывается с TLR4 макрофагов и, активируя эти клетки, вынуждает их продуцировать экстремально высокие уровни сывороточного ТНФ-а, который принимает активное участие в процессах посттравматического воспаления [8]. 
Таким образом, на сегодняшний день существуют достаточно убедительные данные, свидетельствующие о патогенетической значимости изменений в системе врождённого и адаптивного иммунитета при СДС. Это положение является "точкой отсчёта" при обосновании применения средств иммунокоррекции в комплексном лечении такого тяжёлого состояния, как СДС.

Однако интерпретация имеющихся данных об изменениях параметров иммунной системы позволяет оценить колебания показателей в зависимости от степени тяжести и периода развития СДС. Безусловно, иммунопатогенетическая оценка этого тяжёлого состояния будет намного полнее при одновременном анализе досто- верных корреляционных связей изученных показателей. Известно, что патофизиологический анализ не может быть достаточно полноценным без учёта взаимосвязей и патогенетической интерпретации показателей всех органов и систем организма, в т.ч. и системы иммунитета. В медицине наиболее удобный метод оценки взаимосвязей - это корреляционный анализ. И хотя известно, что наличие достоверных корреляционных связей ещё не является доказательством причинно-следственных взаимоотношений, тем не менее, их наличие позволяет сделать предварительные выводы о некоторых патофизиологических закономерностях изучаемых явлений [1]. Именно такой подход и использовался в настоящей работе при анализе полученных результатов.

1. Власов В.В. Эпидемиология. М. ГЭОТАР-Медиа, 2006; с. 272-76.

2. Genthon A.L., Wilcox S.R. Crush syndrome: a case report and review of the literature // J. Emerg. Med. — $2014-$ V.46 — № 2 — P. 313-319.

3. Yang H., Hreggvidsdottir H.S, Palmblad K. et al. A critical cysteine is required for HMGB1 binding to Toll-like receptor 4 and activation of macrophage cytokine release // Proc. Nat. Acad. Sci. USA — 2010 — V.107 — № 26 - P. 1942-1947.

4. Stratos I., Graff J., Rotter R. et al. Open blunt crush injury of different severity determines nature and extent of local tissue regeneration and repair // J. Orthop. Res. - 2010 - V.28 — № 7 - P. 950-957.

5. Harvey E.J., Sanders D.W., Shuler M.S. et al. What s new in acute crush-syndrome? // J. Cardiovasc. Thorac. Res. — 2012 — V.4 - № 4-P. 119-122.

6. Bunn J.R., Canning J., Burke G. et al. Production of consistent crush lesions in murine quadriceps muscle - a biomechanical, histomorphological and immunohistochemical study // J. Orthop. Res. - 2004 - V. 22 — № 6- P. 1336-1344.

7. Кудлай Д.А., Ефремов А.В., Начаров Ю.В. и др. Провоспалительные цитокины сыворотки крови больных с сочетанной и множественной травмой, сопровождающейся рабдомиолизом. // Вестник Российской Военно-медицинской академии - 2007 - Т. 17 — № 1 - С. 49-52.

8. Sqarby M.W., Silva B.A., Peres C.M. et al. Leukocyte infiltration in lung, muscle and liver after limb compression in rats // Pahtophysiology — 2013 — V.20 — № 2 - P. $111-116$. 